\title{
ANALISIS ULANG DINDING PENAHAN TANAH DENGAN PENDEKATAN PERHITUNGAN MANUAL YANG MEMPERHITUNGKAN AKIBAT BEBAN GEMPA
}

\author{
Blasius Gevient ${ }^{1}$ dan Gregorius Sandjaja $S^{2}$ \\ ${ }^{1}$ Program Studi Sarjana Teknik Sipil, Universitas Tarumanagara, Jl. Letjen S. Parman No.1 Jakarta \\ Email: blasiusgevient@yahoo.co.id \\ ${ }^{2}$ Program Studi Sarjana Teknik Sipil, Universitas Tarumanagara, Jl. Letjen S. Parman No.1 Jakarta \\ Email: gregoriuss@ft.untar.ac.id
}

\begin{abstract}
ABSTRAK
Ada beberapa kasus runtuhnya dinding penahan tanah seperti yang terjadi di Perumahan Karina Graha di Desa Jadi, Kediri Tabanan pada akhir Desember 2014 (Wiraga 2014) atau runtuhnya dinding penahan tanah di Underpass Bandara Sukarno-Hatta pada Februari 2018 (Nurdin 2018). Berdasarkan kasus-kasus seperti ini sangatlah penting untuk merencanakan dinding penahan tanah yang bisa menahan beban lateral tanah, baik dalam kondisi statis maupun dinamis. Kestabilan dinding penahan tanah akan dianalisis menggunakan metode perhitungan manual, baik dalam keadaan statis maupun dinamis. Data tanah yang digunakan untuk mendesain dinding penahan tanah berasal dari daerah Lebak Bulus, Jakarta Selatan. Dari kedua perhitungan tersebut didapatkan faktor keamanan pada saat statis dan dinamis yang kemudian akan dibandingkan untuk membuktikan bahwa faktor keamanan pada saat kondisi dinamis lebih kecil dari kondisi statis.
\end{abstract}

Kata kunci: dinding penahan tanah, statis, dinamis, perhitungan manual, faktor keamanan.

\section{PENDAHULUAN}

\section{Latar Belakang}

Dinding penahan tanah (Retaining Wall) adalah bangunan yang berfungsi menstabilkan tanah pada kondisi tanah tertentu khususnya untuk area lereng alam, lereng buatan, dan lereng akibat urugan tanah. Ketika kondisi tanah terganggu akibat beberapa hal tertentu, seperti beban gempa, mesin yang menghasilkan getaran, peledakan, air tanah dan lain-lain yang dapat menurunkan sifat fisik dan sifat mekanik parameter tanah. Hal tersebut dapat mengakibatkan terjadi kerusakan struktur dan membahayakan jiwa manusia. Untuk mengurangi kondisi bahaya tersebut, harus dirancang kestabilan struktur dinding penahan tanah yang mampu menahan beban lateral tanah dan pengaruh beban luar.

Kestabilan dinding penahan tanah akan dianalisis dengan metode konvensional yang mencakup kestabilan guling, geser, dan daya dukung tanah agar dinding penahan dapat dipastikan stabil.

Dalam studi yang akan dilakukan dipilih dinding penahan tanah tipe counterfort, tidak memperhitungkan kekuatan material dinding, dan dilakukan simulasi perubahan parameter tanah untuk mengetahui ketahanan dinding ketika parameter menurun. Dari hasil perhitungan tersebut akan dianalisis stabilitas dinding penahan tanah dengan memperhitungkan gaya statik dan dinamik. Stabilitas yang akan diperiksa terutama kestabilan guling, geser, dan daya dukung. Kemudian akan dilakukan perbandingan antara safety factor keadaan statik dan dinamik.

Studi yang akan dilakukan merupakan sebuah dinding yang sudah dirancang tanpa membuat perhitungan detail tetapi dinding tersebut tetap dapat berdiri stabil. Perbedaan ketinggian tanah yang harus ditahan $7700 \mathrm{~mm}$ dan tebal dinding hanya $250 \mathrm{~mm}$, dengan panjang $4500 \mathrm{~mm}$. Dinding tersebut dilengkapi dengan 4 tiang bor berdiameter 500 mm dengan kedalaman pemancangan $10000 \mathrm{~mm}$.

\section{LANDASAN TEORI}

\section{Dinding Penahan Tanah Tipe Counterfort (Counterfort Wall)}

Dinding ini terdiri dari dinding beton bertulang tipis yang di bagian dalam dinding pada jarak tertentu didukung oleh pelat/dinding vertikal yang disebut counterfort (dinding penguat). Ruang di atas pelat pondasi diisi dengan tanah urug. Apabila tekanan tanah aktif pada dinding vertikal cukup besar, maka bagian dinding vertikal dan tumit perlu disatukan (counterfort). Counterfort berfungsi sebagai pengikat tarik dinding vertikal dan ditempatkan pada bagian timbunan dengan interval jarak tertentu. Dinding counterfort akan lebih ekonomis digunakan bila ketinggian dinding 
lebih dari 7 meter. Menurut ACI, desain dinding penahan tanah counterfort yang proporsional berukuran seperti pada Gambar 1 (Das, 1995).

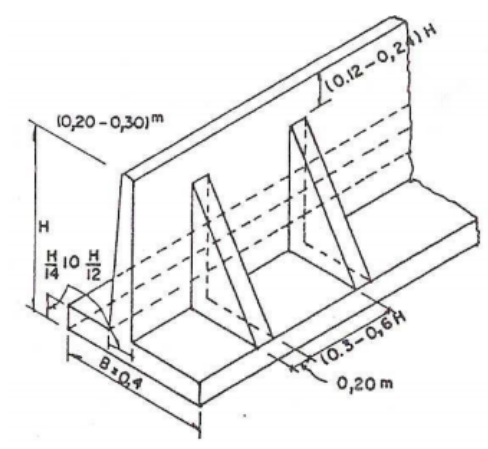

Gambar 1. Dinding Penahan Tanah Tipe Counterfort (Counterfort Wall)

Tekanan Tanah Aktif ( $\left.\mathrm{K}_{\mathrm{a}}\right)$ Menurut Rankine (Das, 1995):

$$
K_{a}=\tan ^{2}\left(45-\frac{\phi}{2}\right)
$$

Tekanan Tanah Pasif $\left(\mathrm{K}_{\mathrm{p}}\right)$ Menurut Rankine:

$$
K_{p}=\tan ^{2}\left(45+\frac{\phi}{2}\right)
$$

Berikut adalah gambar diagram tekanan pada dinding penahan tanah.

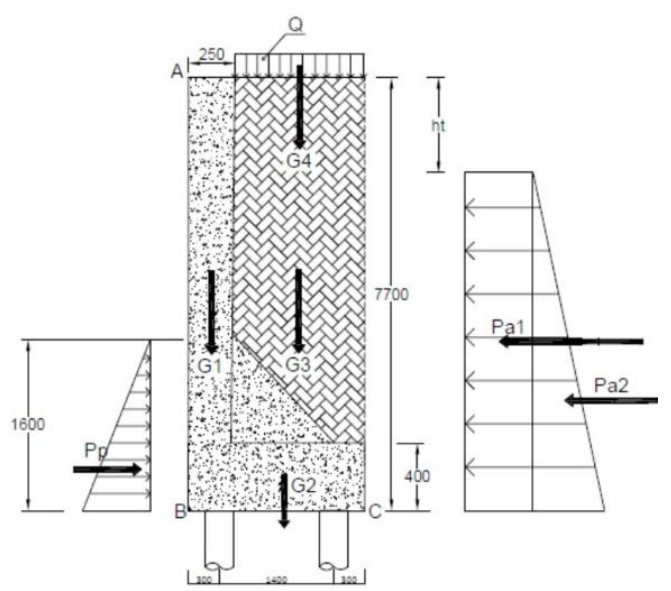

Gambar 2. Diagram Tekanan pada Dinding Penahan Tanah

Untuk tanah kohesif, karena memiliki kohesi maka tekanan tanah lateral dapat dikurangi dengan adanya tension crack (Das, 1995). Tinggi tension crack ht dapat diperoleh dari persamaan:

$$
h t=\frac{2 . c}{\gamma \cdot \sqrt{K_{a}}}
$$

dengan $\mathrm{c}=$ kohesi dan $\gamma=$ berat jenis tanah.

Besar gaya aktif $\mathrm{Pa}_{1}$ dan $\mathrm{Pa} 2$ dapat diperoleh dari persamaan:

$$
P a_{1}=\sigma_{1} \cdot(H-h t)
$$




$$
P a_{2}=\left(\frac{1}{2} \sigma_{2} \cdot(H-h t)\right)
$$

dengan $\mathrm{H}=$ tinggi dinding penahan tanah.

Besar gaya pasif Pp dapat diperoleh dari persamaan:

$$
P p=\left(\gamma \cdot h \cdot K_{p}\right)+\left(2 \cdot c \cdot \sqrt{K_{p}}\right)
$$

dengan $\mathrm{h}=$ tinggi tanah di depan dinding penahan tanah.

\section{Teori Mononobe-Okabe (1924)}

Dalam buku Braja M. Das (1983) diuraikan metode yang dikembangkan berdasarkan metode limit state analysis adalah metode Mononobe-Okabe (Mononobe dan Matsuo, 1929), (Okabe, 1924). Studi pengaruh gempa terhadap tegangan lateral pada struktur penahan tanah pertama-tama dilakukan di Jepang oleh Okabe (1924) dan MononobeMatsuo (1929). Pada metode ini diasumsikan di mana sebuah bidang segitiga tanah (soil wedge) dibatasi dengan sebuah dinding penahan yang kaku.

Tekanan Tanah Aktif menurut Mononobe- Okabe:

$$
P a=\frac{1}{2} \gamma \cdot H^{2} \cdot K_{a}
$$

Dan

$$
K a=\frac{\cos ^{2}(\phi-\beta)}{\cos ^{2} \cdot \beta \cdot \cos (\delta+\beta)\left[1+\left(\frac{\sin (\delta+\phi) \cdot \sin (\phi-\imath)}{\cos (\delta+\beta) \cdot \cos (\beta-\imath)}\right) \frac{1^{-2}}{2}\right]}
$$

dengan $\phi$ = sudut geser tanah, $\beta=$ kemiringan dinding terhadap bidang vertikal, $\delta=$ sudut geser dinding, dan $\imath=$ kemiringan dinding terhadap bidang horizontal.

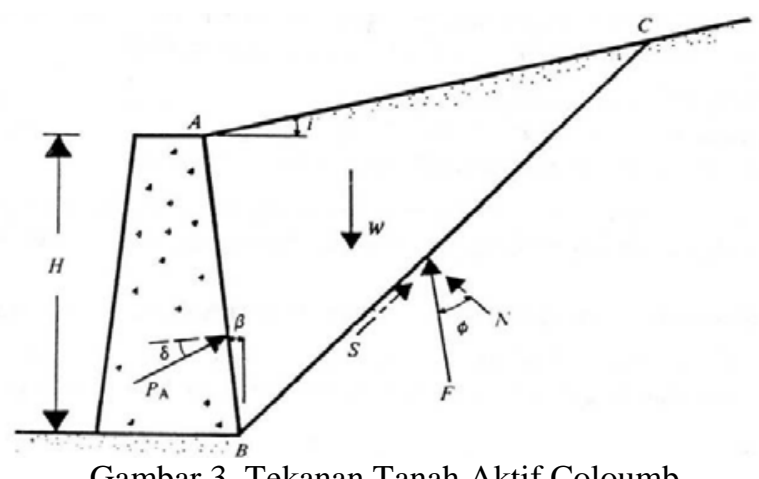

Gambar 3. Tekanan Tanah Aktif Coloumb

Gaya aktif per satuan panjang dinding akibat gempa diperoleh dari persamaan:

$$
P_{A E}=\frac{1}{2} \gamma \cdot H^{2} \cdot(1-k v) \cdot K_{A E}
$$

Koefisien tekanan tanah aktif dengan pengaruh gempa diperoleh dari persamaan:

$$
K_{A E}=\frac{\cos ^{2}(\phi-\theta-\beta)}{\cos \theta \cdot \cos ^{2} \cdot \beta \cdot \cos (\delta+\theta+\beta)\left[1+\left(\frac{\sin (\delta+\phi) \cdot \sin (\phi-\theta-\imath)}{\cos (\delta+\beta+\theta) \cdot \cos (l-\beta)}\right)\right]^{2}}
$$

Dan

$$
\theta=\tan ^{-1}\left[\frac{k h}{(1-k v)}\right]
$$




$$
\begin{aligned}
\text { dengan } \mathrm{kh} & =\frac{\text { percepatan gempa dari komponen horizontal }}{g} \\
\mathrm{kv} & =\frac{\text { percepatan gempa dari komponen vertikal }}{g}
\end{aligned}
$$

Tekanan Tanah Pasif menurut Mononobe- Okabe:

$$
P_{P E}=\frac{1}{2} \gamma \cdot H^{2} \cdot(1-k v) \cdot K_{P E}
$$

Koefisien tekanan tanah aktif dengan pengaruh gempa diperoleh dari persamaan:

$$
K_{P E}=\frac{\cos ^{2}(\phi-\theta+\beta)}{\cos \theta \cdot \cos ^{2} \cdot \beta \cdot \cos (\delta+\theta-\beta)\left[1-\left(\frac{\sin (\delta+\phi) \cdot \sin (\phi-\theta+\imath)}{\cos (\delta-\beta+\theta) \cdot \cos (l-\beta)}\right)\right]^{2}}
$$

Analisis dinding penahan tanah harus memperhitungkan stabilitas guling, geser, dan daya dukung.

Faktor keamanan terhadap bahaya penggulingan $(F g l)$, didefinisikan sebagai berikut:

$$
F_{g l}=\frac{\Sigma M g}{\Sigma M g l}
$$

dengan $\Sigma M g=$ momen penahan dan $\Sigma M g l=$ momen guling.

Faktor keamanan terhadap bahaya geser $(F g s)$, didefinisikan sebagai berikut:

$$
F_{g s}=\frac{\Sigma R h}{\Sigma P a h}
$$

dengan $\Sigma R h=$ gaya penahan dan $\Sigma P a h=$ gaya pendorong geser.

Menurut Terzaghi (1967) kapasitas dukung ultimit pondasi memanjang diperoleh dari persamaan:

$$
q u=c \cdot N c \cdot S c+q \cdot N q+\frac{1}{2} \cdot \gamma \cdot B \cdot N \gamma \cdot S \gamma
$$

\section{Daya Dukung Pondasi Tiang Bor}

$$
Q u=Q p+Q s
$$

dengan Qp = daya dukung ujung tiang dan Qs = daya dukung selimut tiang.

$$
Q p=q p \cdot A
$$

dengan $\mathrm{qp}=$ tahanan ujung per satuan luas dan $\mathrm{A}=$ luas penampang tiang bor.

$$
Q s=f s . A s
$$

dengan $\mathrm{fs}=$ gesekan selimut tiang dan As = luas selimut tiang.

Pada saat menganalisis ulang dinding penahan tanah, 4 pondasi tiang bor berdiameter $500 \mathrm{~mm}$ dan dipancang pada kedalaman $10000 \mathrm{~mm}$ berfungsi memikul momen guling serta gaya pendorong geser pada dinding penahan tanah di atasnya.

\section{METODOLOGI PENELITIAN}

Diagram alir penelitian dapat dilihat pada Gambar 4. 


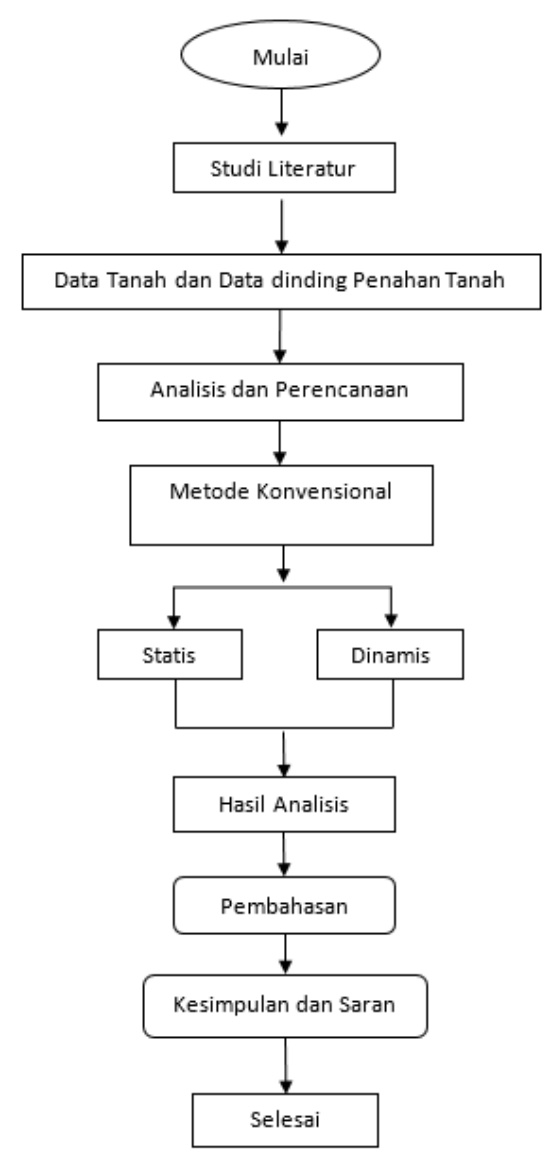

Gambar 4. Diagram Alir Penelitian

\section{ANALISIS DAN PEMBAHASAN}

\section{Dimensi Dinding Penahan Tanah}

Dinding penahan tanah yang akan dianalisis memiliki tinggi $7700 \mathrm{~mm}$ dengan lebar $2000 \mathrm{~mm}$, dan panjang 4500 mm. Pada bagian bawah, dinding penahan tanah dipikul oleh 4 pondasi tiang bor berdiameter $500 \mathrm{~mm}$ dan panjang $1000 \mathrm{~mm}$.

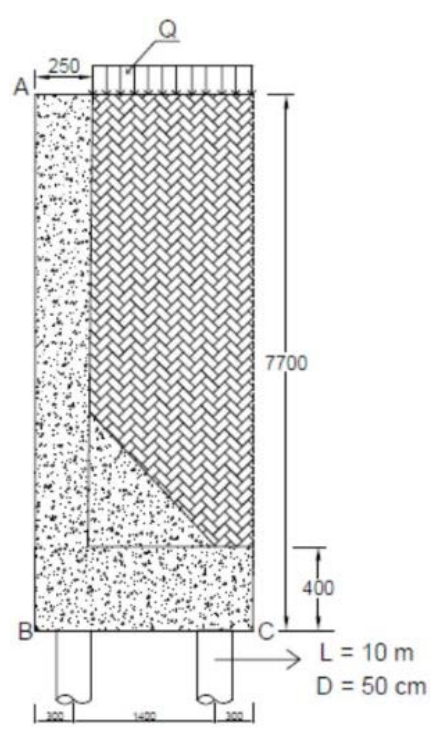

Gambar 5. Dinding Penahan Tanah 
Dengan data tanah sebagai berikut:

$\begin{array}{ll}\text { Berat jenis tanah }\left(\gamma_{w}\right) & =1,65 \mathrm{t} / \boldsymbol{m}^{3} \\ \text { Berat jenis beton }\left(\gamma_{b}\right) & =2,4 \mathrm{t} / \boldsymbol{m}^{3} \\ \text { Kohesi tanah }(c) & =2 \mathrm{t} / \boldsymbol{m}^{2} \\ \text { Sudut geser tanah }(\phi) & =15^{\circ}\end{array}$

\section{Kondisi Statis}

- $\quad$ Tinggi tension crack

$$
\begin{array}{ll}
\text { ht }= & \frac{2 . c}{\gamma \cdot \sqrt{K_{a}}} \\
& =3,159 \mathrm{~m} \\
\text { ht } & \text { Berat tanah dan berat sendiri dinding } \\
\bullet & =4,38 \mathrm{t} \\
\text { G1 } & =1,92 \mathrm{t} \\
\text { G2 } & =21,08 \mathrm{t} \\
\text { G3 } & =0,75 \mathrm{t} \\
\text { G4 } &
\end{array}
$$

- $\quad$ Perhitungan gaya akibat tekanan tanah aktif

$\mathrm{Q}=1 \mathrm{t}$ (beban merata)

$\mathrm{K}_{\mathrm{a}} \quad=0,588$

$\mathrm{Pa}_{1}=16,61 \mathrm{t}$

$\mathrm{Pa}_{2}=11,352 \mathrm{t}$

- $\quad$ Perhitungan gaya akibat tekanan tanah pasif

Pp $=9,696 \mathrm{t}$

- $\quad$ Perhitungan stabilitas guling

Tabel 1. Stabilitas guling kondisi statik

\begin{tabular}{cccc}
$\begin{array}{c}\text { BERAT } \\
\text { (ton) }\end{array}$ & $\begin{array}{c}\text { JARAK } \\
(\mathrm{m})\end{array}$ & $\begin{array}{c}\text { M PENAHAN } \\
(\text { t.m) }\end{array}$ & $\begin{array}{c}\text { M GULING } \\
\text { (t.m) }\end{array}$ \\
\hline 4,38 & 0,125 & 0,5475 & - \\
\hline 1,92 & 1 & 1,92 & - \\
\hline 21,08 & 1,125 & 23,7135 & - \\
\hline 0,75 & 1,125 & 0,84375 & - \\
\hline 9,696 & 0,53 & 5,1712 & - \\
\hline 16,61 & 2,2703 & - & 37,71 \\
\hline 11,352 & 1,5136 & - & 17,182 \\
\hline & & $\Sigma M=32,1974$ & $\Sigma M=54,892$
\end{tabular}

Cek Guling $=\frac{M \text { Penahan }}{M \text { Guling }}=\frac{32,1974}{54,892}=0,586<1,5$

$$
\begin{array}{ll}
\bullet & \text { Perhitungan stabilitas geser } \\
\mathrm{FR} & =\mathrm{c} . \mathrm{B}+\mathrm{W} \tan \phi \\
\mathrm{C} & =2 \mathrm{t} / \mathrm{m}^{2} \\
\phi & =15^{\circ} \\
\mathrm{W} & =\mathrm{G} 1+\mathrm{G} 2+\mathrm{G} 3+\mathrm{G} 4 \\
& =28,13 \mathrm{t} \\
\mathrm{FR} & =2 \times 2+28,13 \tan 15^{\circ} \\
& =11,537 \mathrm{t}
\end{array}
$$

$$
\begin{aligned}
\text { Gaya penahan geser } & =\mathrm{FR}+\mathrm{Pp} \\
& =11,537+9,696 \\
& =21,233 \mathrm{~T}
\end{aligned}
$$


Gaya pendorong geser $\quad=\mathrm{Pa}$

$$
=27,962 \mathrm{t}
$$

Cek Geser $=\frac{\text { Gaya penahan }}{\text { Gaya pendorong }}=\frac{21,233}{27,962}=0,759<1,5$

- $\quad$ Perhitungan daya dukung

$$
\begin{aligned}
\text { Dik :c } & =2 \mathrm{t} / m^{2} \\
\phi & =15^{\circ} \\
\mathrm{H} & =7,7 \mathrm{~m} \\
\mathrm{~B} & =2 \mathrm{~m} \\
\mathrm{\gamma} & =1,65 \mathrm{t} / \mathrm{m}^{2} \\
\Sigma \mathrm{V} \quad & =\mathrm{G} 1+\mathrm{G} 2+\mathrm{G} 3+\mathrm{G} 4 \\
\Sigma \mathrm{Mo} \quad & =(\mathrm{G} 3 \times 0,125)+(\mathrm{G} 4 \times 0,125)+(\mathrm{Pp} \times 0,533)-(\mathrm{G} 1 \times 0,875)-(\mathrm{Pa} 1 \quad \mathrm{x} 2,2703)-(\mathrm{Pa} 2 \times 1,5136) \\
& =-51,1 \mathrm{t}) \\
& =\frac{\Sigma V}{A} \pm \frac{\Sigma M}{w} \\
& =\frac{28,128}{2 \times 4,5} \pm \frac{51,1}{3} \\
\sigma^{+} & =20,158 \mathrm{t} / m^{2} \\
\sigma^{-} & =-13,9 \mathrm{t} / m^{2}
\end{aligned}
$$

Karena $\phi=15^{\circ}<28^{\circ}$, maka digunakan rumus Terzaghi untuk kondisi local shear failure.

$$
\begin{aligned}
\mathrm{Nc} & =9,7 \\
\mathrm{Nq} & =2,7 \\
\mathrm{~N} \gamma & =0,9 \\
\mathrm{qu} \quad & =\text { c.Nc.Sc }+ \text { q.Nq }+0,5 \cdot \text {. } . \text { B.Ny.Sy } \\
& =2 \times 9,7 \times 1+(1 \times 1,75) \times 2,7+0,5 \times 1,65 \times 2 \times 0,9 \times 1 \\
& =25,61 \mathrm{t} / \mathrm{m}^{2} \\
\text { qu } \quad & =\frac{25,61}{3}=8,53 \mathrm{t} / \mathrm{m}^{2}
\end{aligned}
$$

$\sigma=20,158 \mathrm{t} / \mathrm{m}^{2}>\mathrm{qu}=8,53 \mathrm{t} / \mathrm{m}^{2}$ (tidak memenuhi)

\section{Kondisi Dinamis}

- Menghitung koefisien tegangan tanah lateral aktif

$$
\begin{aligned}
\phi & =15^{\circ} \\
\beta & =0 \\
i & =0 \\
\mathrm{Kv} & =0 \\
\mathrm{~K}_{\mathrm{h}} & =\frac{0,378 g}{g}=0,378 \\
\theta & =\tan ^{-1}\left[\frac{K_{h}}{\left(1-K_{v}\right)}\right]=\tan ^{-1}\left[\frac{0,378}{(1-0)}\right]=20,706 \\
K_{A E}= & \frac{\cos ^{2}(\phi-\theta-\beta)}{\mathrm{K}_{\mathrm{AE}}} \\
P_{A E}= & \frac{1}{2} \gamma \cdot H^{2} \cdot(1-k v) \cdot K_{A E} \\
\mathrm{P}_{\mathrm{AE}} & =48,18 \mathrm{t} / m^{2}
\end{aligned}
$$

- Menghitung koefisien tegangan tanah lateral pasif 


$$
K_{P E}=\frac{\cos ^{2}(\phi-\theta+\beta)}{\cos \theta \cdot \cos ^{2} \cdot \beta \cdot \cos (\delta+\theta-\beta)\left[1-\left(\frac{\sin (\delta+\phi) \cdot \sin (\phi-\theta+\imath)}{\cos (\delta-\beta+\theta) \cdot \cos (\imath-\beta)}\right)\right]^{2}}
$$

$\mathrm{K}_{\mathrm{PE}} \quad=0,743$

$P_{P E}=\frac{1}{2} \gamma \cdot H^{2} \cdot(1-k v) \cdot K_{P E}$

$\mathrm{P}_{\mathrm{PE}} \quad=3,681 \mathrm{t} / \mathrm{m}^{2}$

Berat $\left(\mathrm{G}_{\mathrm{T}}\right)$ tanah dan dinding penahan tanah pada kondisi dinamis adalah 29,016 t.

- $\quad$ Perhitungan stabilitas guling kondisi dinamis

Tabel 2. Stabilitas guling kondisi dinamis

\begin{tabular}{cccc}
$\begin{array}{c}\text { BERAT } \\
\text { (ton) }\end{array}$ & $\begin{array}{c}\text { JARAK } \\
(\mathrm{m})\end{array}$ & M Penahan (t.m) & $\begin{array}{c}\text { M Guling } \\
(\mathrm{t} . \mathrm{m})\end{array}$ \\
\hline 4,38 & 0,125 & 0,5475 & - \\
\hline 1,92 & 1 & 1,92 & - \\
\hline 21,08 & 1,125 & 23,7135 & - \\
\hline 1,636 & 1,125 & 1,8405 & - \\
\hline 3,681 & 0,53 & 1,951 & - \\
\hline 48,18 & 2,705 & - & 109,39 \\
\hline & & $\Sigma \mathrm{M}=29,97$ & $\Sigma \mathrm{M}=109,39$ \\
\hline
\end{tabular}

Cek Guling $=\frac{M \text { Penahan }}{M \text { Guling }}=\frac{29,975}{109,39}=0,27<1,1$

- Perhitungan stabilitas geser

$$
\begin{array}{ll}
\mathrm{FR} & =\mathrm{c} . \mathrm{B}+\mathrm{W} \tan \phi \\
\mathrm{c} & =2 \mathrm{t} / \mathrm{m}^{2} \\
\phi & =15^{\circ} \\
\mathrm{W} & =\mathrm{G} 1+\mathrm{G} 2+\mathrm{G} 3+\mathrm{G} 4 \\
\mathrm{FR} & =29,016 \mathrm{t} \\
& =2 \times 2+29,016 \tan 15^{\circ} \\
& =11,77 \mathrm{t}
\end{array}
$$

Gaya penahan geser $\quad=\mathrm{FR}+\mathrm{Pp}$

$$
=11,77+3,681
$$

Gaya pendorong geser $\quad=\mathrm{Pa}$

$$
=15,451 \mathrm{t}
$$

$$
=48,18 \mathrm{t}
$$

Cek Geser $=\frac{\text { Gaya penahan }}{\text { Gaya pendorong }}=\frac{15,45 i}{48,18}=0,32<1,5$

- $\quad$ Perhitungan daya dukung

$$
\begin{aligned}
\text { Dik :c } & =2 \mathrm{t} / \mathrm{m}^{2} \\
\phi & =15^{\circ} \\
\mathrm{H} & =7,7 \mathrm{~m} \\
\mathrm{~B} & =2 \mathrm{~m} \\
\mathrm{\gamma} & =1,65 \mathrm{t} / \mathrm{m}^{2} \\
\Sigma \mathrm{V} \quad & \mathrm{G} 1+\mathrm{G} 2+\mathrm{G} 3+\mathrm{G} 4 \\
& =29,016 \mathrm{t} \\
\Sigma \mathrm{Mo} \quad & =(\mathrm{G} 3 \times 0,125)+(\mathrm{G} 4 \times 0,125)+(\mathrm{Pp} \times 0,533)-(\mathrm{G} 1 \times 0,875)-(\mathrm{Pa} \times 2,705) \\
\sigma \quad & =-125,53 \mathrm{t} . \mathrm{m} \\
& =\frac{\Sigma V}{A} \pm \frac{\Sigma M}{w}
\end{aligned}
$$




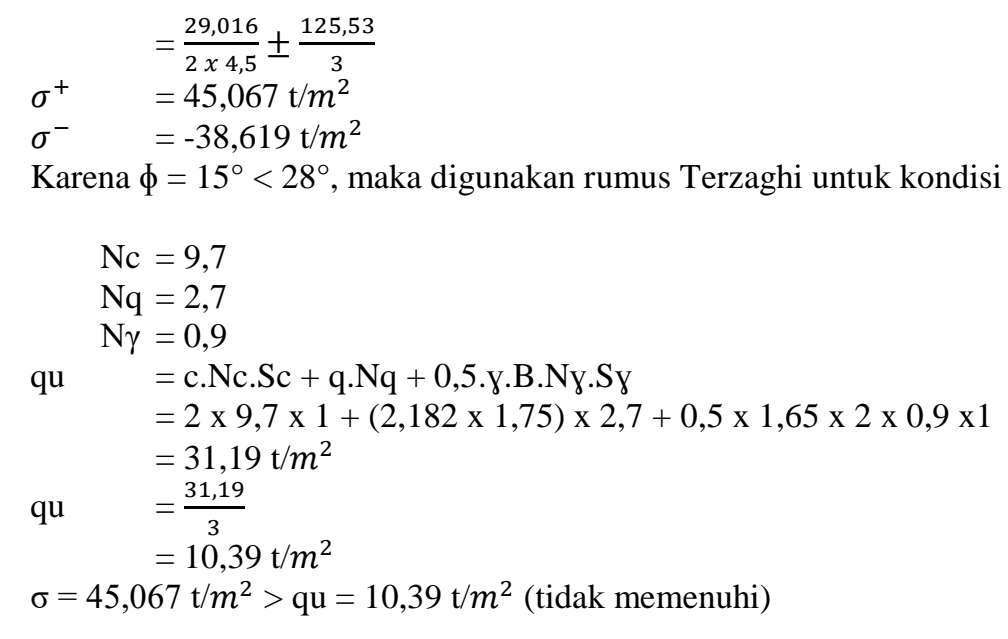

\begin{tabular}{|c|c|c|c|}
\hline \multicolumn{4}{|c|}{ Tabel 3. Momen dan SF } \\
\hline Kondisi & $\begin{array}{c}\text { Momen Penahan } \\
\text { (t.m) }\end{array}$ & $\begin{array}{c}\text { Momen Guling } \\
\text { (t.m) }\end{array}$ & SF \\
\hline Statik & 32,1974 & 54,892 & 0,586 \\
\hline Dinamik & 29,975 & 109,39 & 0,27 \\
\hline \multicolumn{4}{|c|}{ Tabel 4. Gaya Pendorong dan SF } \\
\hline Kondisi & $\begin{array}{c}\text { Gaya Penahan } \\
\text { (ton) }\end{array}$ & $\begin{array}{l}\text { Gaya Penderong } \\
\text { (ton) }\end{array}$ & SF \\
\hline Statik & 21,233 & 27,962 & 0,759 \\
\hline Dinamik & 15,451 & 48,18 & 0,32 \\
\hline
\end{tabular}

Pada saat kondisi statis dan dinamis, dari analisis dinding penahan tanah yang dilakukan, stabilitas geser, guling, dan daya dukung tanah tidak dapat ditahan oleh dinding penahan tanah itu sendiri. Oleh karena itu, momen yang mengakibatkan guling dan gaya geser yang terjadi di dinding penahan tanah akan dipikul oleh tiang bor yang berada di bawah dinding penahan tanah tersebut.

\section{Daya Dukung Tiang Bor}

$$
\begin{array}{ll}
\mathrm{Q}_{\mathrm{T} \text { ijin }} & =128,08 \mathrm{t} \\
\mathrm{Q}_{\mathrm{P}} & =73,84 \mathrm{t} \\
\mathrm{Q}_{\mathrm{S}} & =98,544 \mathrm{t} \\
\mathrm{H}_{\mathrm{U}} & =38,805 \mathrm{t}
\end{array}
$$

Pada kondisi statis, gaya tekan yang diterima oleh tiang sebesar 88,219 t lebih kecil dari daya dukung ijin tiang yaitu $128,08 \mathrm{t}$ dan gaya tarik yang diterima oleh tiang sebesar 88,219 t juga lebih kecil dari daya dukung selimut tiang yaitu 98,544 t. Gaya geser yang diterima oleh tiang bor sebesar 31,457 t juga lebih kecil dari daya dukung lateral tiang yaitu 38,805 t. Dari beberapa perbandingan tersebut dapat disimpulkan bahwa pondasi tiang bor aman dalam menerima beban dari dinding penahan tanah yang berada di atasnya.

Untuk keadaan dinamik, terdapat momen guling sebesar 109,39 ton yang mengakibatkan gaya tekan dan gaya tarik pada tiang bor sebesar 175,8 ton. Gaya tekan tiang 175,8 ton tersebut lebih besar jika dibandingkan dengan daya dukung ijin tiang bor yaitu 128,08 ton. Begitupun dengan gaya tarik tiang 175,8 ton yang juga lebih besar dari daya dukung selimut tiang yaitu 98,544 ton. Dari perbandingan tersebut dapat disimpulkan bahwa pada kondisi dinamis tiang bor tidak aman dalam memikul dinding penahan tanah yang berada di atasnya.

\section{KESIMPULAN}

- Berdasarkan hasil analisis perhitungan stabilitas guling, terjadi penurunan safety factor dari keadaan statis senilai 0,586 menjadi 0,27 pada keadaan dinamis.

- Pada saat kondisi statis, momen guling pada stabilitas guling dan gaya pendorong pada stabilitas geser tidak dapat dipikul oleh dinding penahan tanah. Gaya-gaya yang bekerja pada dinding penahan tanah tersebut dipikul semuanya oleh 4 tiang bor yang berada di bawah dinding penahan tanah dan masih dinyatakan aman. 
- Pada saat kondisi dinamis konstuksi dinding penahan tanah memiliki kemungkinan menjadi tidak stabil karena kemampuan daya dukung tiang bor tidak cukup untuk menahan beban-beban dinamik

\section{SARAN}

- $\quad$ Pada saat merancang dinding penahan tanah harus memperhitungkan akibat beban pada saat gempa.

- Perhitungan kestabilan guling, geser, dan daya dukung tanah dinding penahan tanah harus dilakukan dengan benar dan teliti agar tidak akan terjadi kegagalan pada dinding penahan tanah ketika beban dinamis bekerja.

\section{DAFTAR PUSTAKA}

Das, Braja M.(1995). Mekanika Tanah (Prinsip - Prinsip Rekayasa Geoteknis) Jilid 1. Jakarta: Penerbit Erlangga. Das, Braja M.(1995). Mekanika Tanah (Prinsip - Prinsip Rekayasa Geoteknis) Jilid 2. Jakarta: Penerbit Erlangga. Das, Braja M.(1983). Principles of Soil Dynamic. Boston: PWS - KENT Publishing Company.

Terzaghi, Karl and Peck, B Ralph. (1967), Soil Mechanics in Engineering Practice, Second Edition. New York: John Wiley \& Sons. 